\title{
Familial isolated trichomegaly
}

INSERM

\section{Source}

INSERM. (1999). Orphanet: an online rare disease and orphan drug data base. Familial isolated trichomegaly. ORPHA:411788

Familial isolated trichomeg aly is a rare genetic hair anomaly characterized by a prolonged anagen phase of the eyelash hairs, leading to extreme eyelash growth that may result in corneal irritation. Increased growth of hair on other parts of the face (eyebrows, cheeks, forehead) and/or the body (chest, arms, legs) may be associated. 